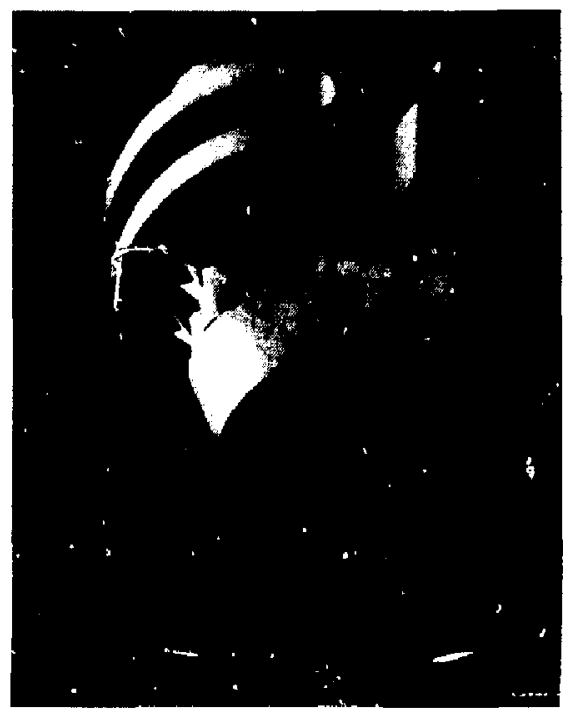

\title{
STRUCTURA' ANALYSIS OF THE MAGNET SYSTEM FOR MIRROR FUSION TEST FACILITY (MFTF)
}

ADDENDUM I

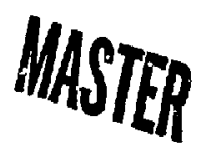

GENLRAL DYNAMIES Convair Division 


\section{STRUCTURAL ANALYSIS OF THE MAGNET SYSTEM FOR MIRROR FUSION TEST FACILITY (MFTF)}

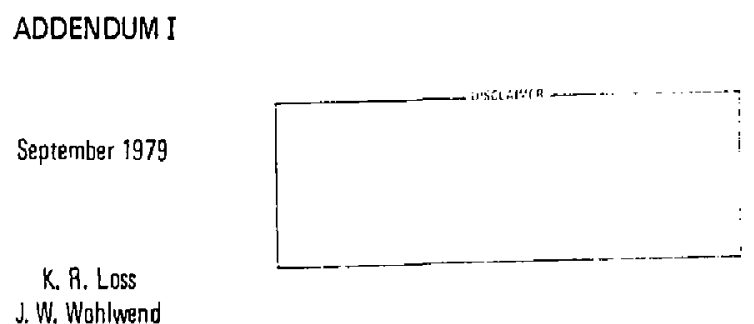

Prepared Under

Contract 9815603

Prepared for

UNIVERSITY OF CALIFORN!A LAWAENCE LIVERMOAE LABORATOAY

P.0. BOX $5012(L-446)$

Livermore, California 94550

Prepared by

GENERAL DYNAMICS CONVAIR DIVISION

P.0. B0x 80847

San Oiego. California 92138 
THIS DOCUMITNT WAS PREPARED BY

GENERAL DYNAMTCS/CONVAR

AND APPROVED BY
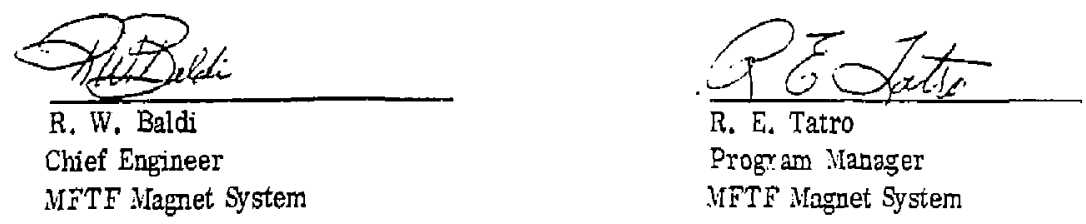


\section{CONTENTS}

SECTION

$\underline{\text { PAGE }}$

1

RTRODUCTION

$1-1$

2

NASTRAN AND GDSAP FINTTE ELEMENT MODELS

$2-1$

2.1 Model Definition

$2-1$

2.2 Model Refinements

$2-1$

3

REFINED STRESS ANALYSIS OF NASTRAN AND GDSAP MODELS 3-1

3.1 Background

$3-1$

3.2 Stress Analysis

$3-1$

3.3 Bending Moment Distributions

$3-9$

4

REF ERENCES

4-1

Appendix A

Appendix B

Appendix C 


\section{FIGURES}

Figure

$\underline{\text { Page }}$

2.1 MFT'F-Refined Model for GDSAP and NASTRAN Analyses

2.2 MFTF-Refined Model and Rod Elements

2.3 Breakdown of Finite Element Model Components

3.1 Magnet Case Principal Stresses-Magnetic Load Only

3.2 Magnet Case Principal Stresses- Magnetic Ioad Only

3.3 Magnet Case Principal Stresses-Magnetic and Thermal Loads

3.4 Magnet Case Principal Stresses-Magnetic and Thermal Loads

3.5 Wagnet Case Longitudinal Stresses-Magnetic Load Only

3.7 Transition from $3.2^{\prime \prime}$ to $5.0^{\prime \prime}$ Thick Plate for the Inner Crossover Plate

Transverse Bending Moment Distribution-Nagnetic Load Only

3.11 Transverse Bending Moment Distribution-Nagnetic Load Only $\quad 3-15$

3.12 Longitudinal Bending Moment Distribution-Magnetic Load Only 3-16 


\section{SUMMARY}

The stress analysis refinement of the MFTF magnet system using GDSAP (General Dynamics Structural Analysis Program) and NASTRAN finite element computer models has been completed. The objective of this analysis was to calculate a more reined case and jacket stress distribution. The GDSAP model was refined in the minor radius area to yield a more detailed prediction of the stress distributions in critical areas identified by the previous analysis (Reference 1). Modifications in the case plate thickness (from 3. 0 inches to 3.2 inches) and in the conductor pack load distribution and stiffness were included. The GDSAP model was converted to an identical NASTRAN model to deter mine the influence on stress results using higlier order elements.

Results showed reduced stresses from the previous analysis in the critical regions of the minor radius. For the normal electromagnetic load, the critical load case, peak principal stresses of $81.5 \mathrm{ksi}$ and $83.3 \mathrm{ksi}$ were predicted by the NASTRAN and GDSAP analyses, respectively. This compares to the $88 \mathrm{ksi}$ peak stresses determined by our previous analysis. The peak stress was found to always occur at $45^{\circ}$ from the axis of symmetry in the inner crossover plate of the minor radius. When thermal induced loads were compatibly superimposed on the electromggnetic loads, predicted peak stresses were reduced to $79.8 \mathrm{ksi}$ and $81.2 \mathrm{ksi}$ for the NASTRAN and GDSAP analyses respectively.

In general these results are good. The 1.5 factor of safety on yield strength for the 304 LN case material is satisfied for the entire magnet when NASTRAN is used as the analysis tool for the combination of magnetic and thermal loadings. GDSAP shows the most critical area to be locally stressed only $1,5 \%$ greater than the $80 \mathrm{ksi}$ allowable stress for the worst compatible load case (i.e., electromagnetic combined with residual thermal).

Overall, this refinement analysis has verified the structural integrity of the MIFTF magnet system. 


\section{INTRODUCTION}

This report details the refinement of the UFTF magnet system finite element model and summarizes the resulting stress analysis. Sitention was focused on the effect of using a finer mesh of elements in the minor radius of the magnet system f $c r$ obtaining a more accurate prediction of the stresses in this area. The previous finite element aralysis (Reference 1) showed critical stresses occurring in the minor radius.

Finite element analyses using NASTRAN and GDSAP pragrams were conducted. Major refinem snts included the following:

- Elements in a 50 degree span in the minor radius were located at 10 degree increm ents versus the 25 degree incremants used in the previous model.

o A 3.20 inch case plate thichness was used, reflecting the actual thiciness of the case now being constructed versus the 3.00 inch case thickness used in previous analysis.

- The electromagnetic load distribution has been refined and moceled correctly.

- NASTRAN utilizes hither order elements than GDSAP and accounts for transverse shear flexibility.

- The offset of the neutral surfaces at the transition from 3.20 inch to 5.00 inch thick: plates for the inner and intermodiate cross-over plates is now modeled.

- There is a reduced num'jer of triangular and no highly distorted quadrilateral elements. This tends to improve the accuracy of the finite-element analysis.

A discussion of the model is given in Section 2. Detailed docum antation of the refined finite element model is provided in Appendix $A$. Sections of this model have been plotted using NASTRAN graphics program. The sama model geometry was used for both NASTRAN and GDSAP.

Comparisons of stress and bending moment distributions as predicted by this model and the previous model are made in Section 3. The loading conditions analyzed included 
the normal electromagnetic load case, a $500 \mathrm{psi}$ internal case quench pressure, the $4.5 K$ operating temperature residual stress condition, and a combination of the electromagnetic and thermal loads.

Complete output data listings from the NAST'RAN and GDSAP computer runs are found in Appendices B and C, respectively. 


\section{NASTRAN AND GDSAP FINITE ELEMENT MODELS}

\subsection{Model Definition}

The basic modeling techniques used in the previous analysis (Reference 1) were also used for this refinement analysis. The magaet system was modeled using a quarter-symmetric 6600 degree of freedom model (Figures 2.1-2.3) with symmetric loading. Model refinements were made only in the minor radius sections of both coils. The case and jacket structure was modeled by isoparametric quadrilateral elements; CQUADI for GDSAP and CQUAD4 for NASTRAN. The sane model geometry and loading distribution were used for both GDSAP and NASTRAN,

\subsection{Nodel Refinements}

Elements are now located at approxim ately 10 degree intervals throughout the whole minor radius. Previously elements had been located at 25 degree intervals in the 50 degree span bordering on the transition from in ajor to minor radius, and elements at 10 degree increments through the remaining 40 degree spas. A group of narrow elements now span the transition from inajor to minor radius (Figure 2.3a). These rows of narrow elements in the inner and intermediate crossover plates are inclined to the plane of the bordering crossover elements. This models the offset of the riid-surfaces at the transition from 3.20 inch thick to 5.00 inch thick crossover plates. This element geometry is also discussed in Section 3, and is illustrated in Figure 3.7.

The conductor pack is modeled by six continuous rod elements representing the lumped axial stiffness of the conductor coils. These rods were connected to the case and jacket structure in the transverse directions by additional rod elements. The effective cross sectional areas of these transverse rod elements were modified from the previous analysis to account for the finer $m$ esh of the new $m$ adel. Expermentally determined elastic moduli (Reference 5) were incorporated to best approximate the conductor pack stiffness in these directions. The magnetic loads as supplied by LLI (Reference 4) were also redistributed to the nodes in accordance wilh refined mesh. Careful attention was paid to insure the lumped 
forces on the rod element nodes were properly oriented within the pack.

The case plate thickness for this model was revised from 3.00 inches to 3.20

inches. This revision reflects the actual case plate now being used in the construction of the actual magnet case. 


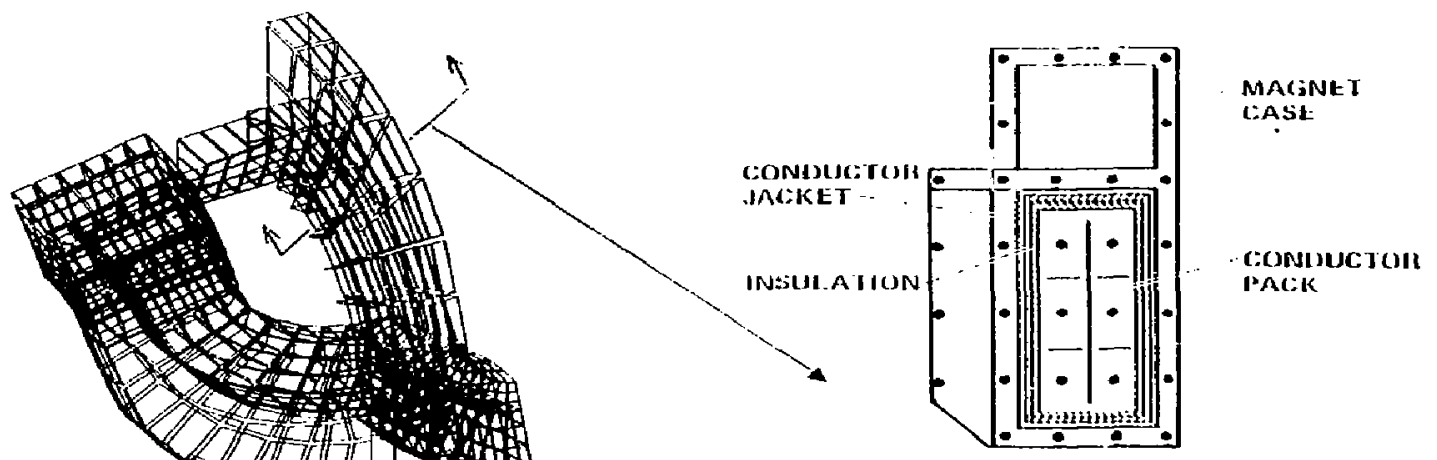

(A) I YPILAR. TWOHL AtIIINNGGLMEN

$x$

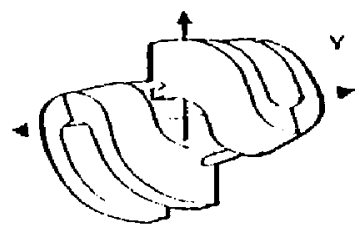

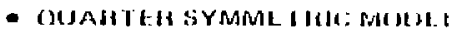

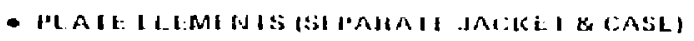

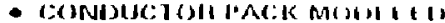

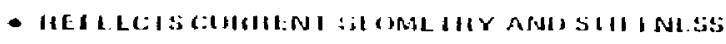

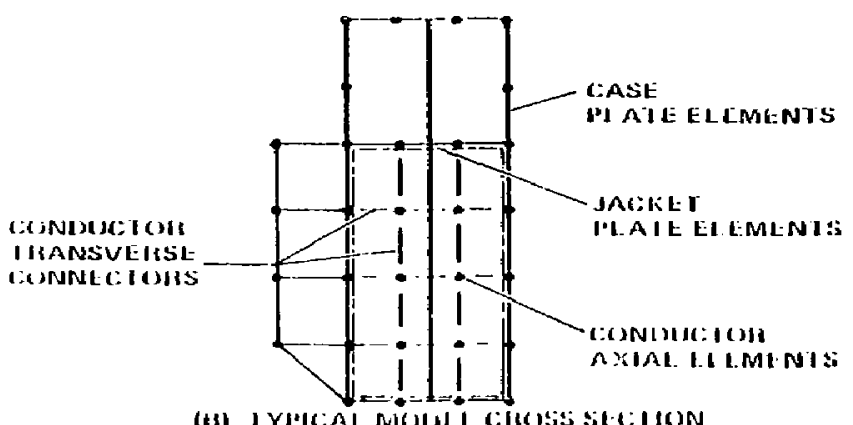

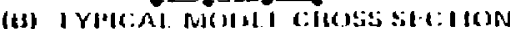

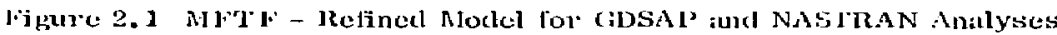




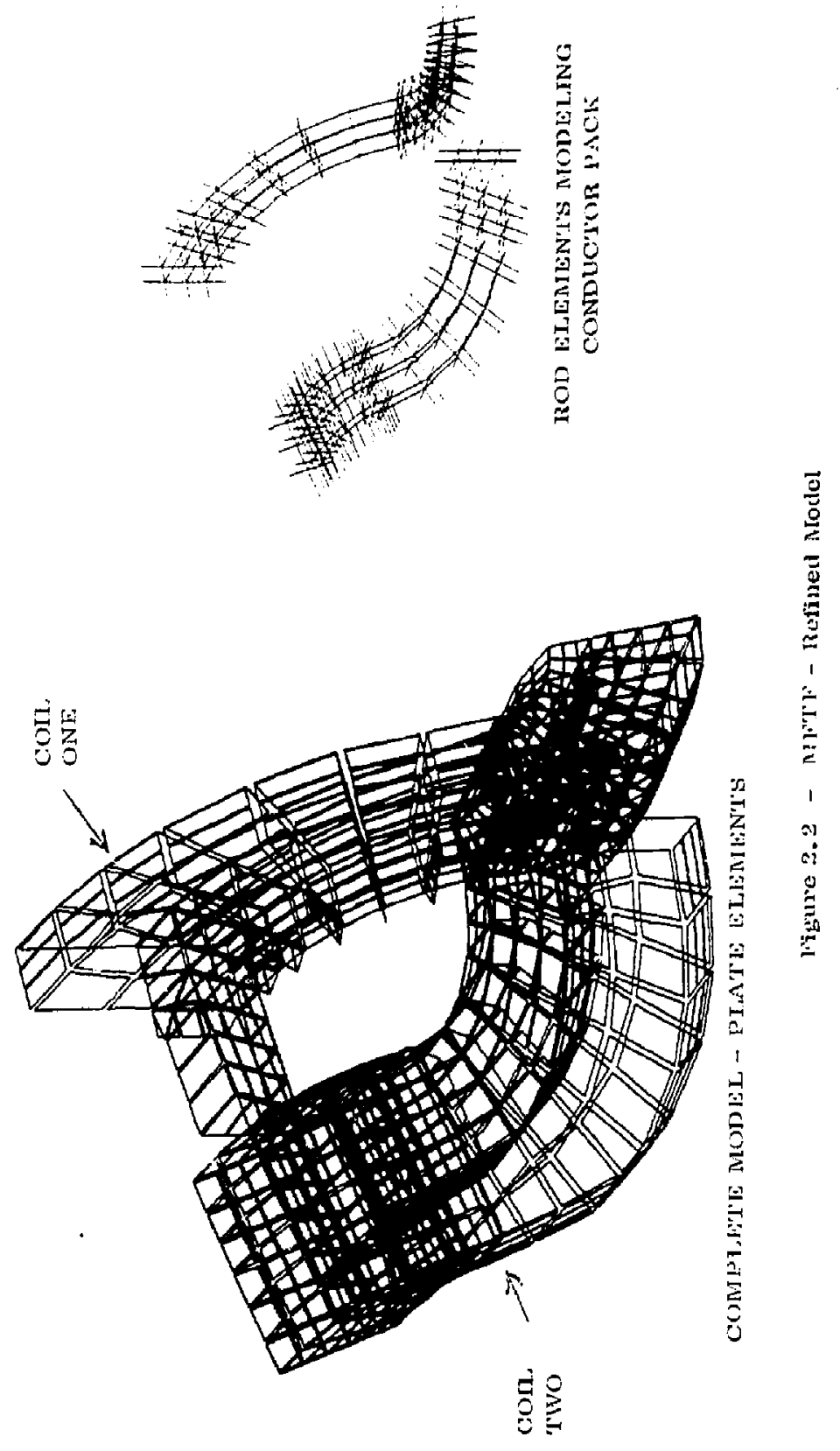




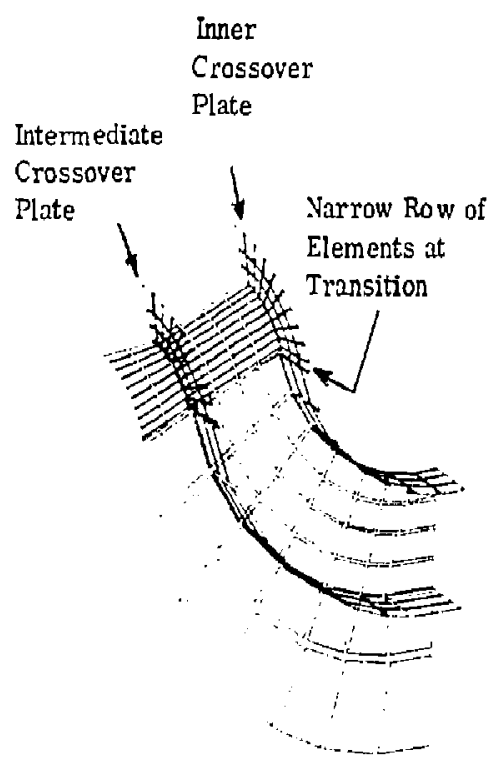

a) Inner case plate inner and intermediate crossover plates

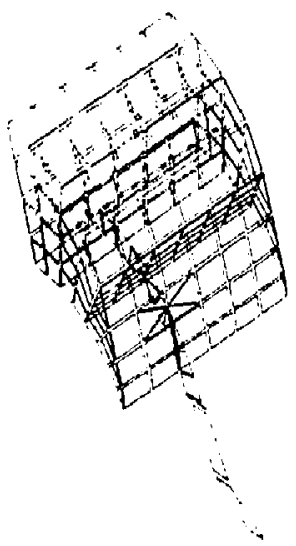

c) Coil extension structure (with ribs) and intermeid

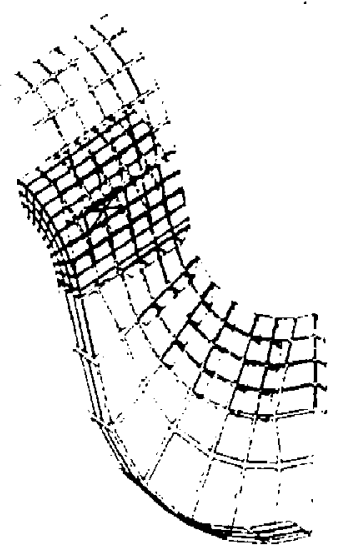

b) Outer case plate, outer crossover plate, coil extension shell, and stifiñers

Coil Extension Cover

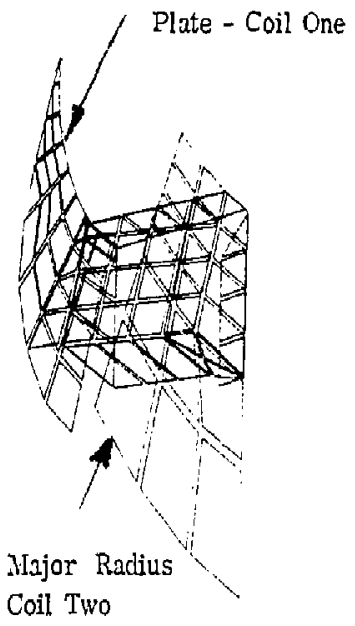

d) Lower Intercoil Structure (rotaterl for better view')

Figure 2.3 - Breakdown of Finite Element Model Components 


\section{REFTED STRESS ANALYSIS OE NASTRAY AND CDSAP MODELS}

\subsection{Background}

The NASTRAN and GDSAP analyses results for the refined model are summarized in Figures 3.1-3.12. The same geometry and loading distributions were used for both models. All data reported here has been taken from roil num ber two (Figure 2.2). In the graphs shown the lines titled "Baseline GDSAP Analysis" refer to data reported previously (Reference 1) from the original model. Lines titled, "Refired MASTRAN", and 'Relined CDSAP", refer to new dat" from the refined model. The sign convention for bending mom snts used by VASTRAX, deining positive bending moments as causing compression in fibers of the positive z surface, is used for all graphs.

\subsection{Stress Anolinis}

The maxim am principal stresses predicted in the critical regions of the minor radius showed reductions of $\mathrm{g}^{\prime \prime}$, to $8^{\prime \prime}$, for WATRAN and $0^{\prime *}$, to $7^{\circ}$, , for GDSAP from those predicted by the previous model. The largest stresses occurred with electromagnetic londing applied by itself.

For this loading situation the N.LSTRAN analysis found the peak principal stress of $81.5 \mathrm{ksj}$ occurring at $43^{\circ}$ from the axis of symmetry in the inner crossover plate of the minor radius (Figure 3.1). This was the only location showing a stress larger than the $80 \mathrm{ksi}$ allowable stress level for the NASTRAN analysis. The GDSAP analysis found stresses above $80 \mathrm{ksi}$ over allowable stress level for the NASTRAN analysis. The GDSAP analysis found stresses above $80 \mathrm{ksi}$ over a 25 degree span with a peak stress of $83.4 \mathrm{ksi}$ (Figure 3.1). These stresses represent reductions of $7 \%$ by NASTRAN and $5 \%$ by GDSAP from the previously predicted peak principal stress of $88 \mathrm{ksi}$.

These reductions can be attributed to several tictors. The increase in the case plate thickmess from 3.00 inches to 3.20 inches results in an increase of $6.7 \%$ in membrane stiffness and an increase of $21 \% 0$ in bending stiffiness. A simple reduction of stresses by these factors (mexirnum bending stresses would be reduced 
by $12(7)$ could not be assumed however, because the increase in the stiffness of the entire casie causes a larger force to be reacted in the minor radius. Reduced stresses by ay average of about $3 .$, is observed in the XISTRA. GDSAP analysis (Figure 3.1-3.4). NASTRAN uses higher order elements and includes for transverse shear flexibility which together account for the differences. Finally, the finer mesh, while m inly intended for a more detailed look at the stress behavior in the minor redius, represents the curvature more closeiy and hence reduces the modeling discontinuities in this area.

GDSAP stresses also exceeded the $\$ 0 \mathrm{ksi}$ level slightly for the intermediate crossover plate over a 10 degree span at the axis of symmatry with a peak stress of 81. $\mathrm{ksi}$ (Figure 3.2). NASTRAN predicted all stresses below $80 \mathrm{ksi}$ in this area.

When the residual thermal loads due to the cooidown from ruom semperature to 4. $5 \mathrm{~K}$ operaing tomperature are superimposed on the electromagnetic loads. a slight recluction of stresses is obtained (Figure 3.3 and 3.4). It is important to note for this load combination that NASTRAN showed all stresses in the mignet to be below the $80 \mathrm{ksi}$ desigr allowable stress level. CDSAP predicted a peak prircipal stress of $31.2 \mathrm{ksi}$, with a span of 10 degrees in the inner crossover piete at stresses over $80 \mathrm{ksi}$ (Figure 3.3). The interm adiate crossaver plate, for this load com'jination, showed a peak principle stress of $80.6 \mathrm{ksi}$ at the axis of symmatry (Figure 3. 4 ).

Comparisons between the previous and current models of selected longitudinal and transverse memiorane stresses are shown in Figures 3.5 and 3.6. The GDSAP and NASTRAN malyses both predicted essentiallv the same stresses in all sections as the previous analysis except the cham fer area of the minor radius (Figure 3.6). The differences here are attributed to modeling charses. In the previous analysis, the chamfer was modeled with triangular plate elements (see Appendix $A$, Reference 1). In the refined model this area was modeled with quadilateral plate elements, Actual stresses in this area most likely fall between these predictions. 


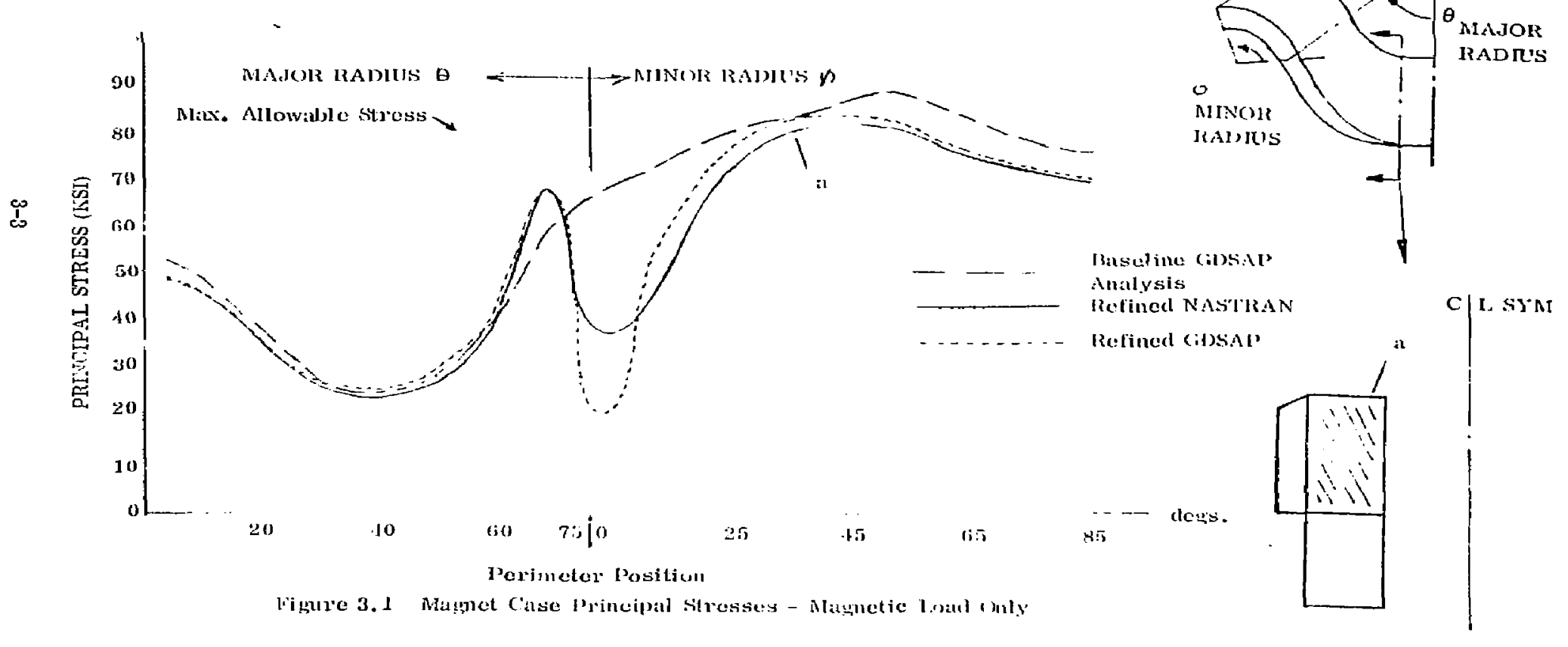



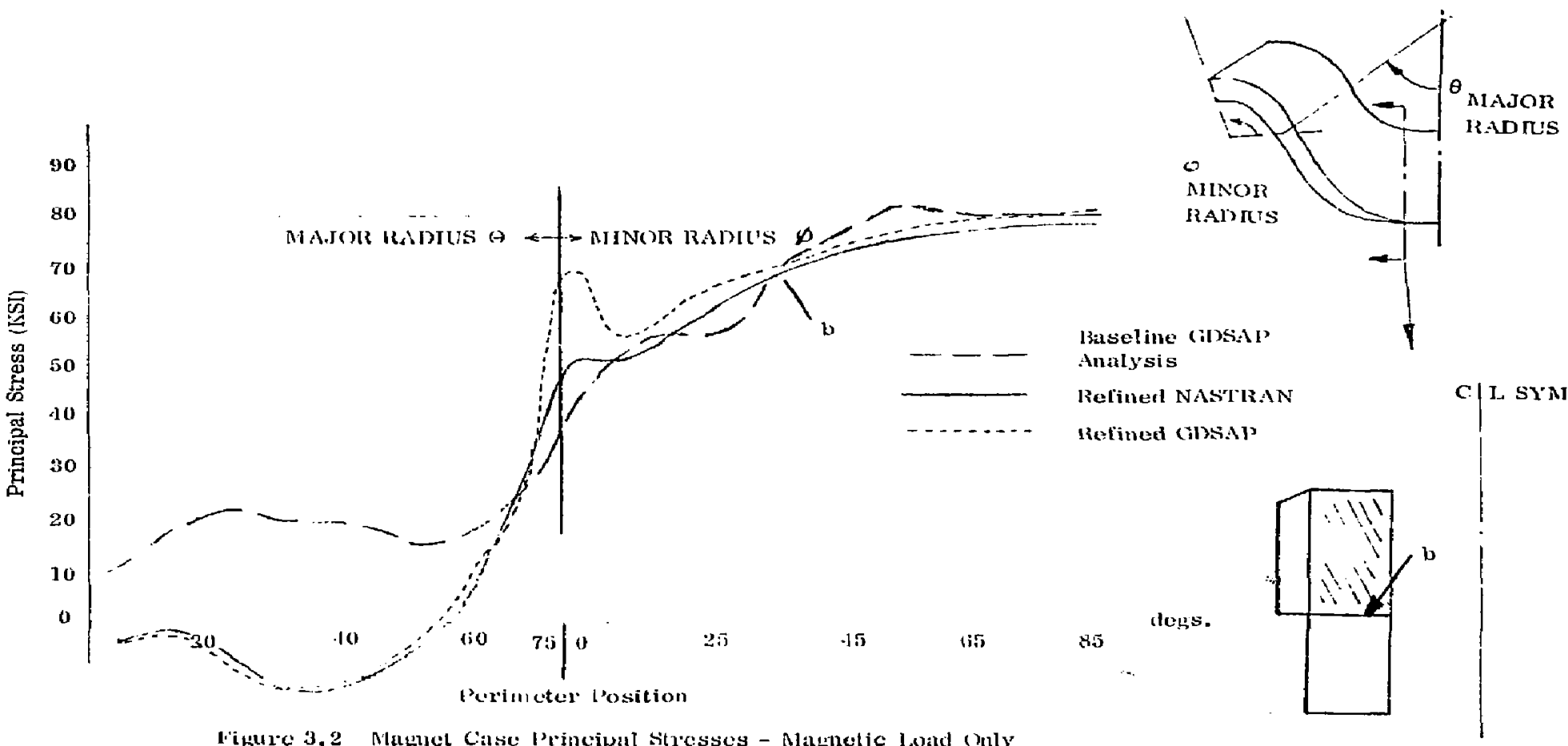

rigure 3.2 Maguel Case Prineipal Stresses - Magnetic load Only 

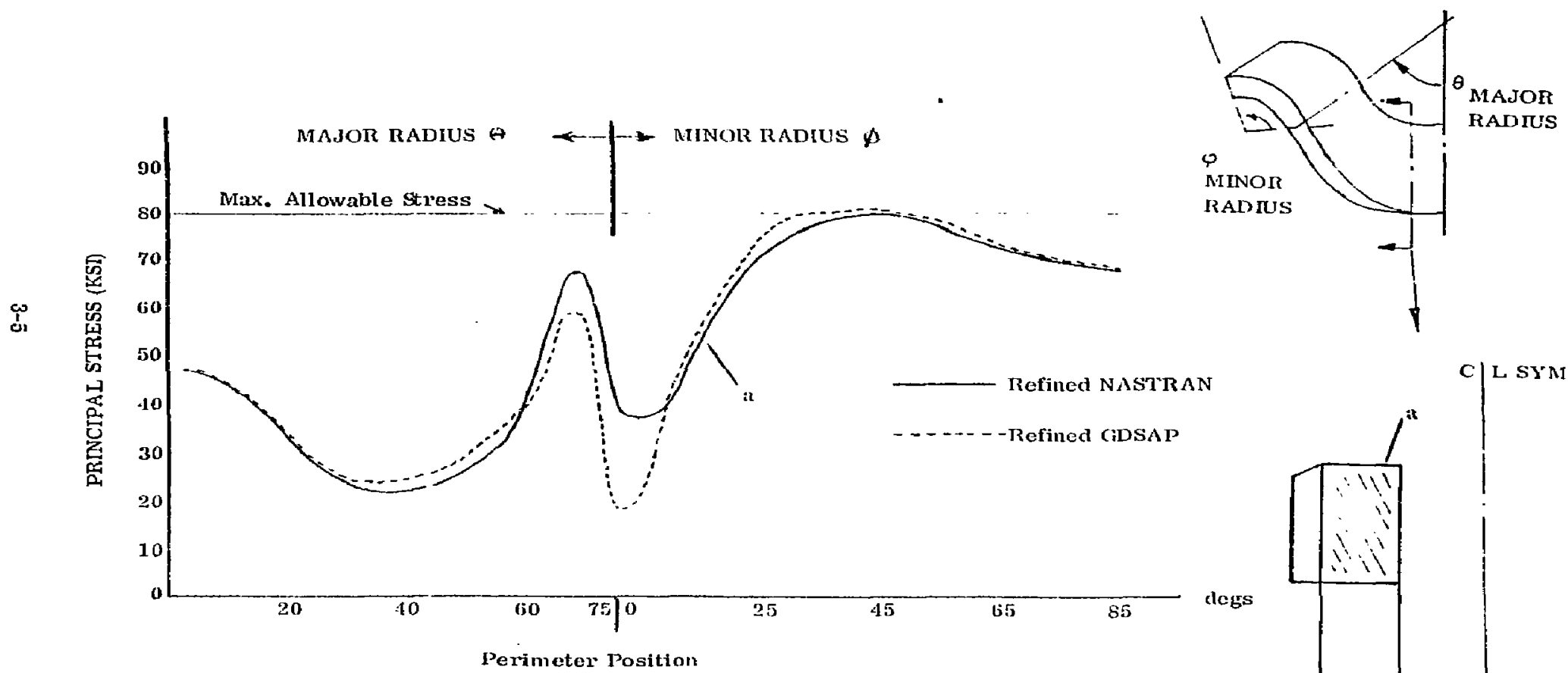

rigure 3.3 Magnet Case Principal Stresses - Nabnetic and 'llermal 1.ouds

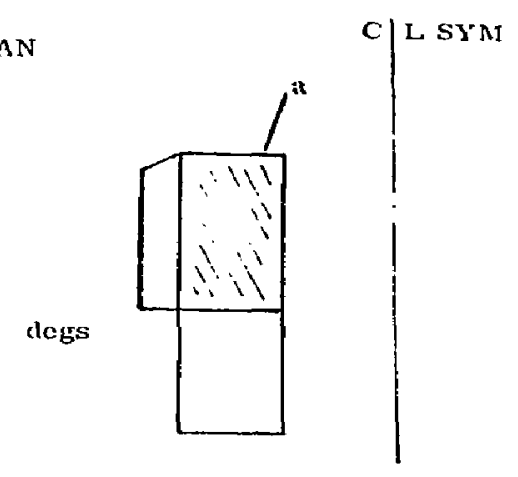




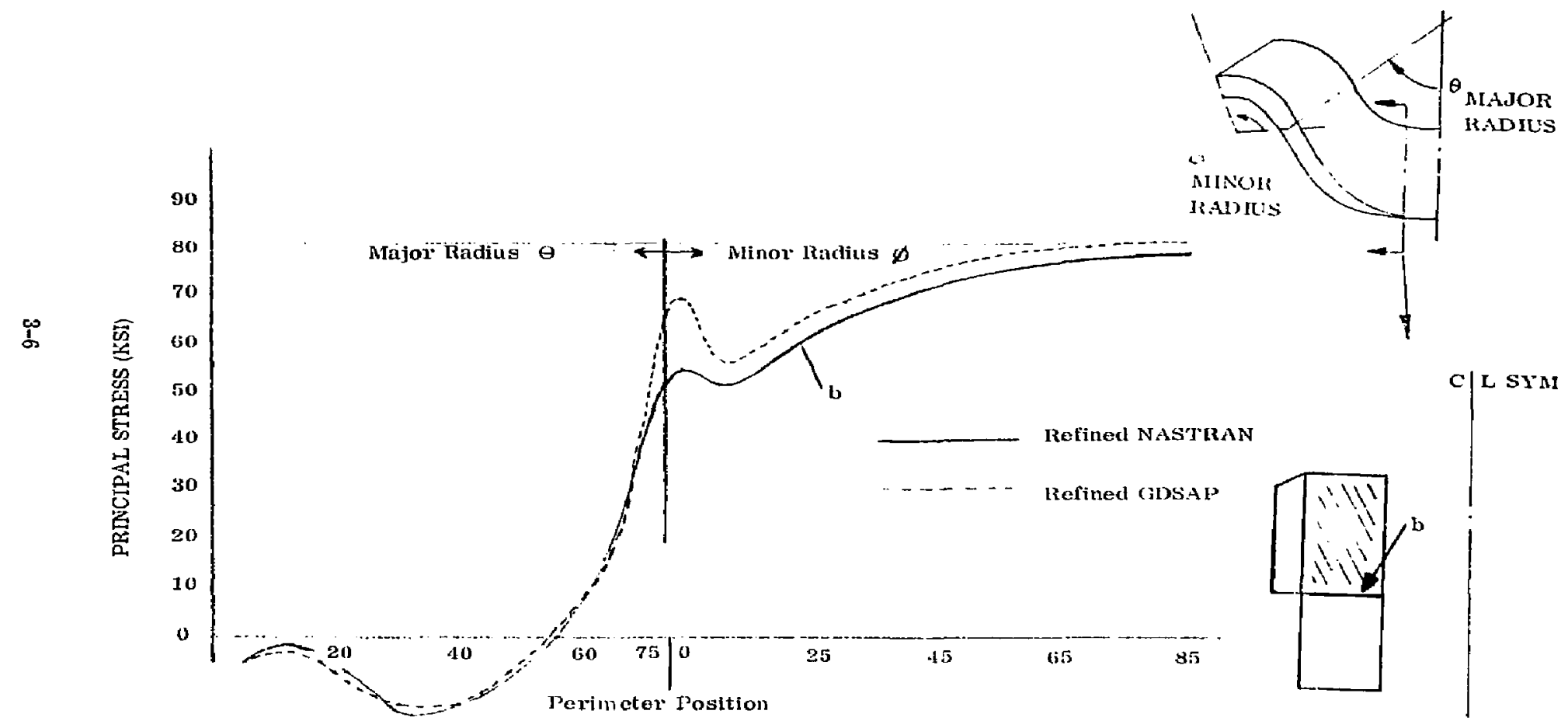

Figure 3.4 Magnet Case Principal Stresses - Magnetic and Thermal 

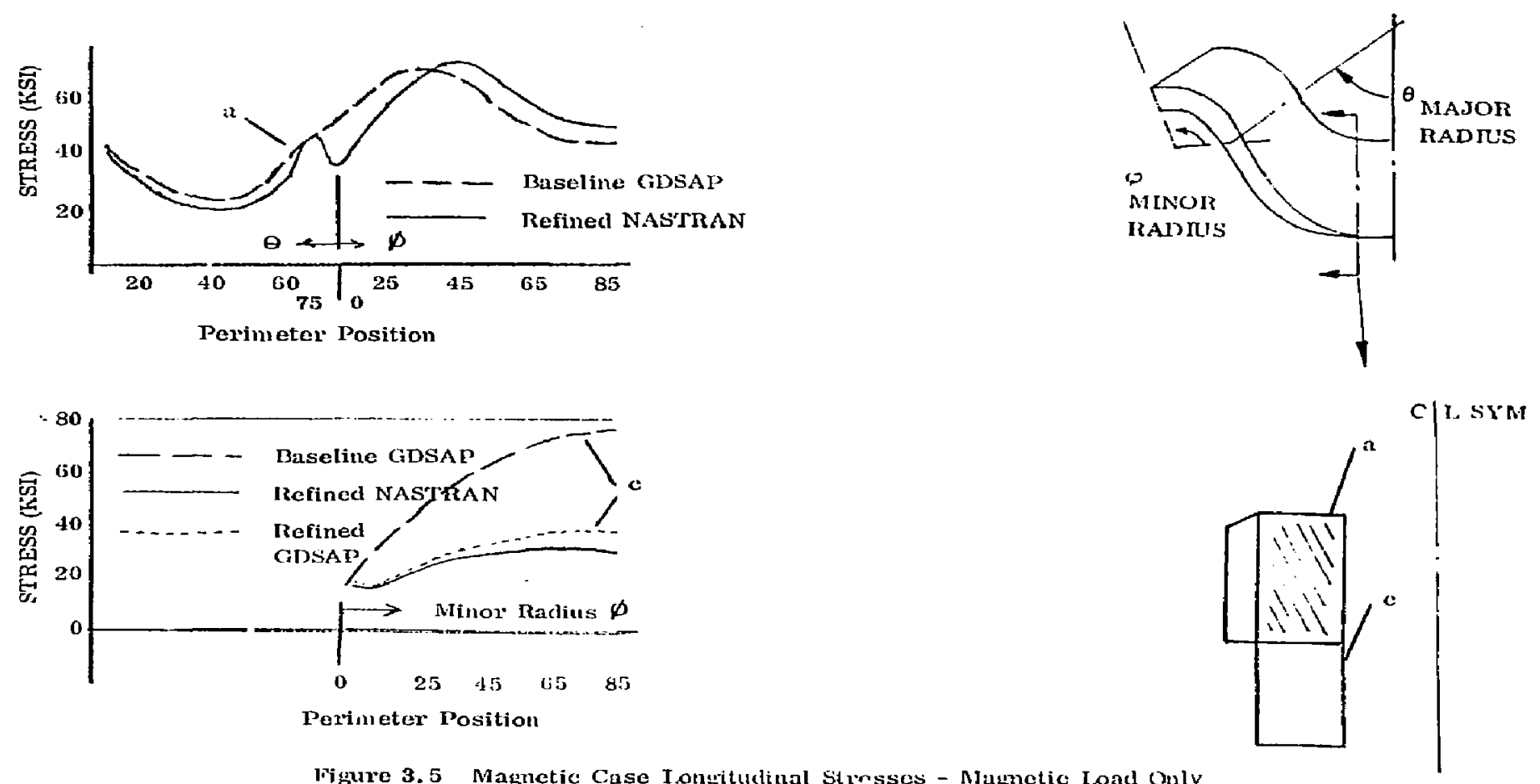

Pigure 3.5 Magnetic Case Ionyitudinal Strosses - Naynetic Ioad Only 


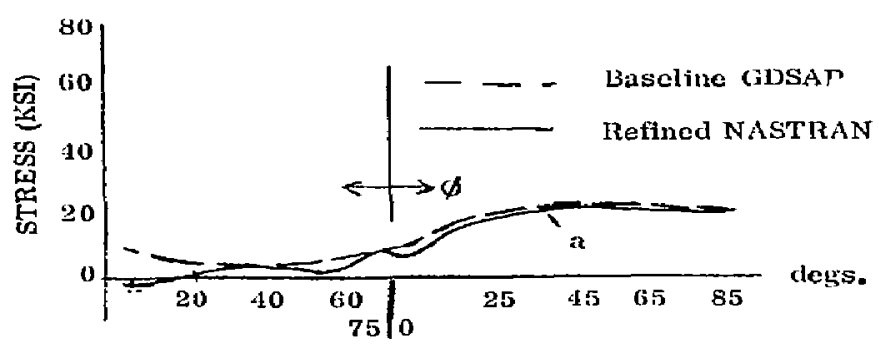

$\underset{\infty}{\infty}$

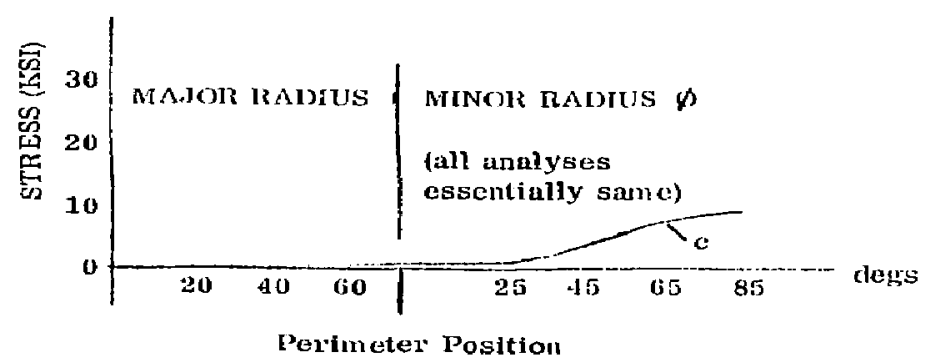

ligme 3.6 Mixgnetic Case 'Trtungverso stresses - Magnetic Loud Only
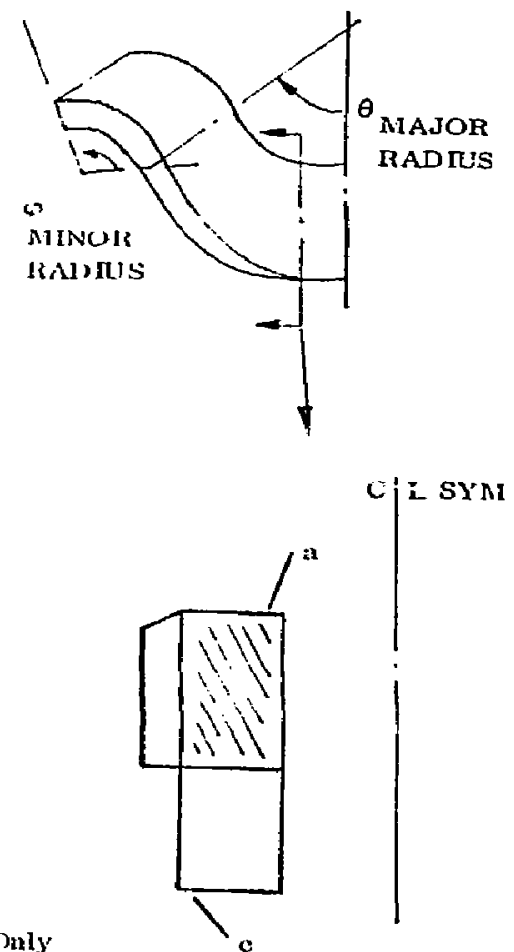


\subsection{Bending Moment Distributions}

The transverse bending moment distributions did show some deviations from the previous analysis (Figures $3.8-3,12$ ). Large discontinuities in the transverse bending moment due to the mis-alignment of the neutral axis are found at the transition from the 3.20 inch to the 5.00 inch thick crossover plates. A transverse bending moment is here defined as one causing transverse bending stresses; hence, a transverse bending moment acts about a longitudinal axis (this was the convention used in the previous report). Discontinuties would obviously be expected in the longitudinal bending moment distribution due to the discontinuity of the neutral surface and do show up in the anaiyses (Figure 3.12). But, the large discontinuities in the transverse bending moments are somawhat surprising. They do exist, however, although not to the extent shown here.

The transverse $r$ anding moments arise from the constraining of the longitudinal bending deform ations by the relatively stiff case side plates as illustrated by Figuie 3.7. The memirrane stresses in this area are large tensions at the inner radius and lower tension at the outer radius. Therefore, larger discontinuities would be expected nearer the inner radius than the outer radius as seen in Figures $3.8-3.11$.

Another cause of this large increase in that the transw erse moment vectors for these transition elements are inclined at significant angies $\left(-30^{\circ}\right)$ to the moment vectors of neighboring elements. Hence only that component in the plane of the remaining crossover plate elements might be considered correct. Therefore, while these discontinuities do exist, they are not as large as predicted here. Models with a higher density of elements in the transition area are necessary to obtain better results.

The appreciable differences in the bending moments predicted by GDSAP and NASTRAN at the discontinuity can be attributed to the "crude" approximation of just one row of elements modeling the transition. Differences in the program's 
element formation methods have a large effect here. Their predictions of bending moments would be expected to converge with the increase in the number of elements in this area.

No drostic effect on the local stress levels is seen at the plate thickness transition (Figure 3.1-3.6) since secondary bending effects are, in general, smaller than overall or primary bending effects which cause the membrane stresses.

Residual thermal stresses and quench condition intermal pressure stresses are very low in comparison to electrom agnetic induced stresses, and cause no si ructural problems. 


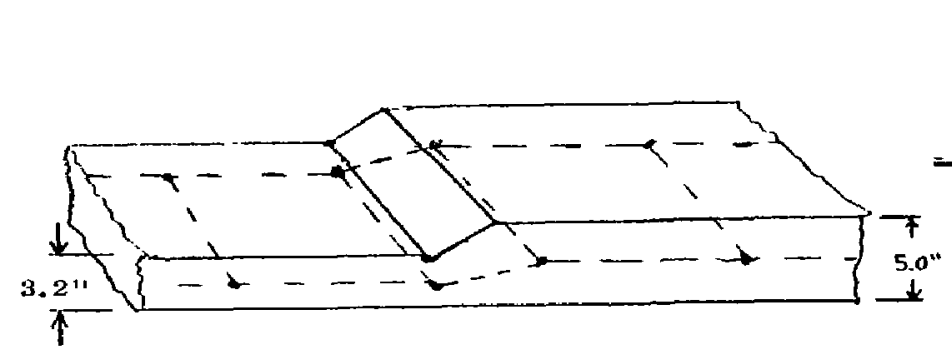

Transition Boing Mocleled

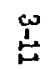

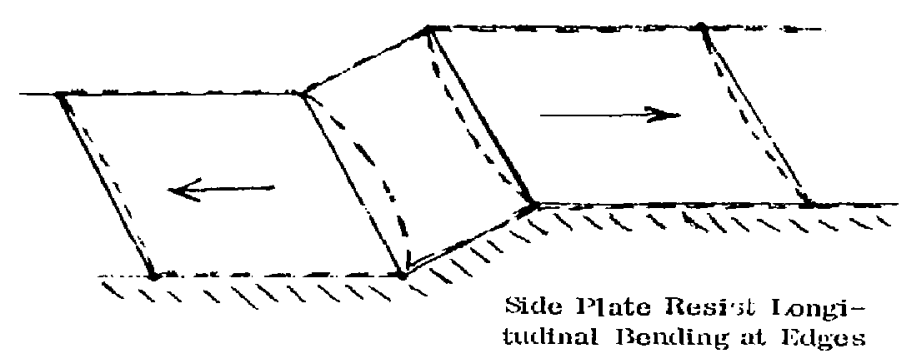

Actual Beformations Which lutuce Transverse Bending Mom culs Due to Siele Plate Constraints

\section{Neighboring lilements in Tension}

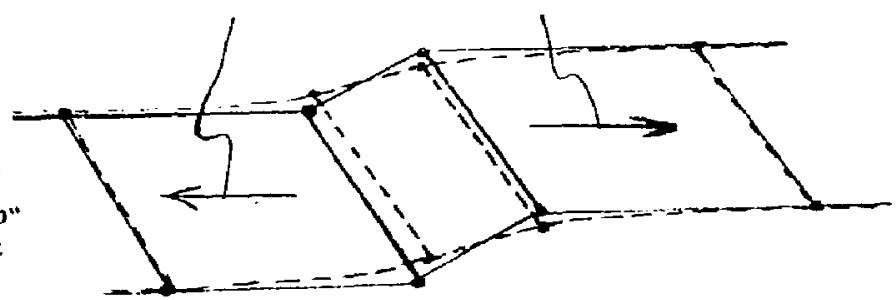

Desired r:eformation if Unconstraned

$-$

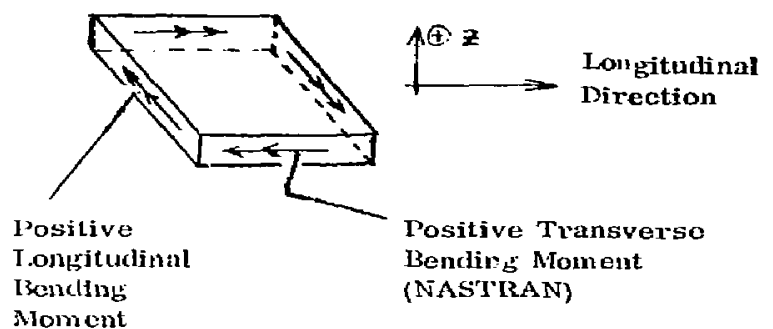

10ment

Bendivg Moment

Moment

Figure 3.7 - 'Irausition from 3.3" to 5.0" Thick l'lite for the Inner Crossover 1'late 


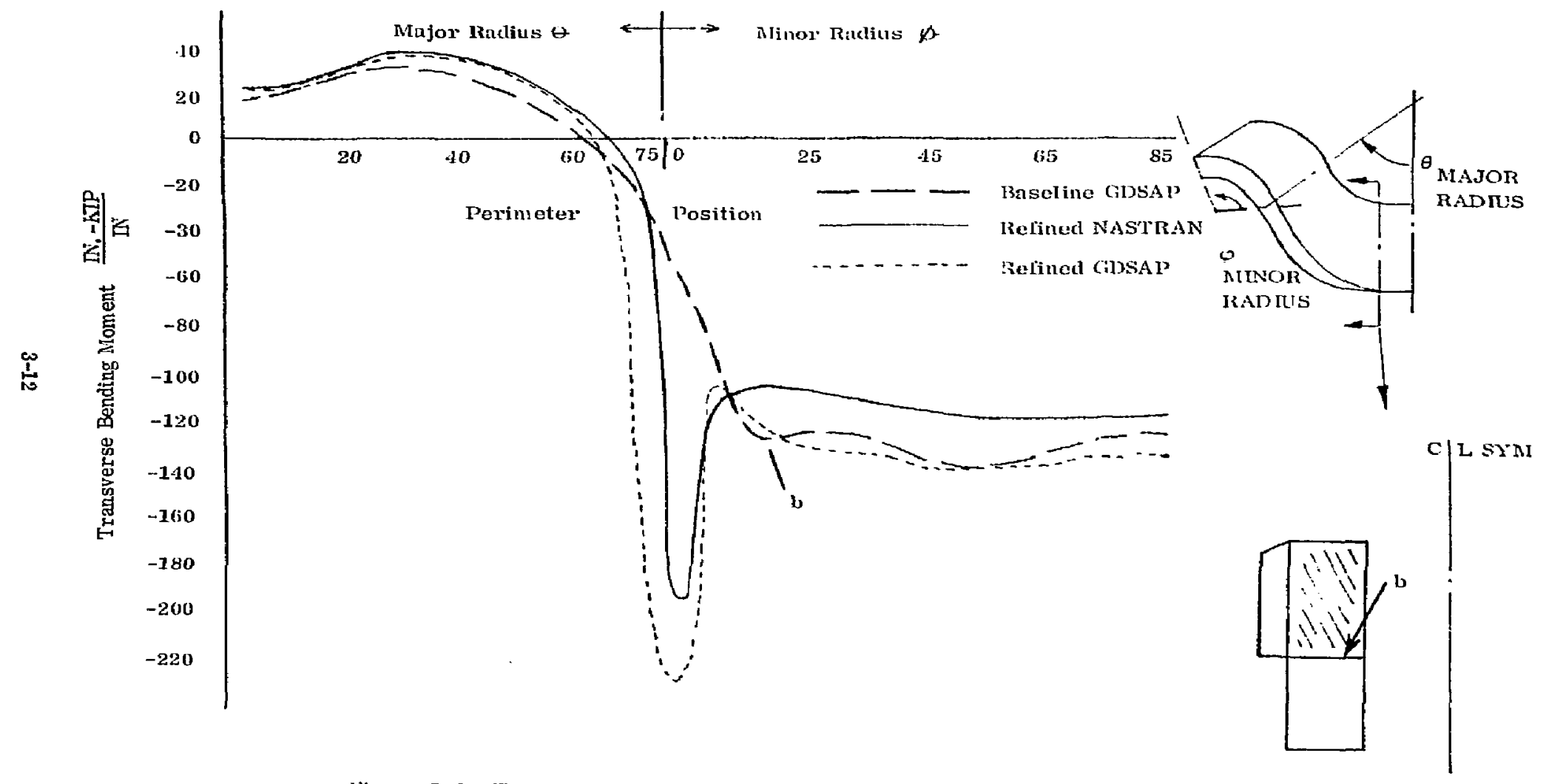

l'igure 3.8 'Trunsverse Bending Moment Distribution-Mlitghetic lout only 


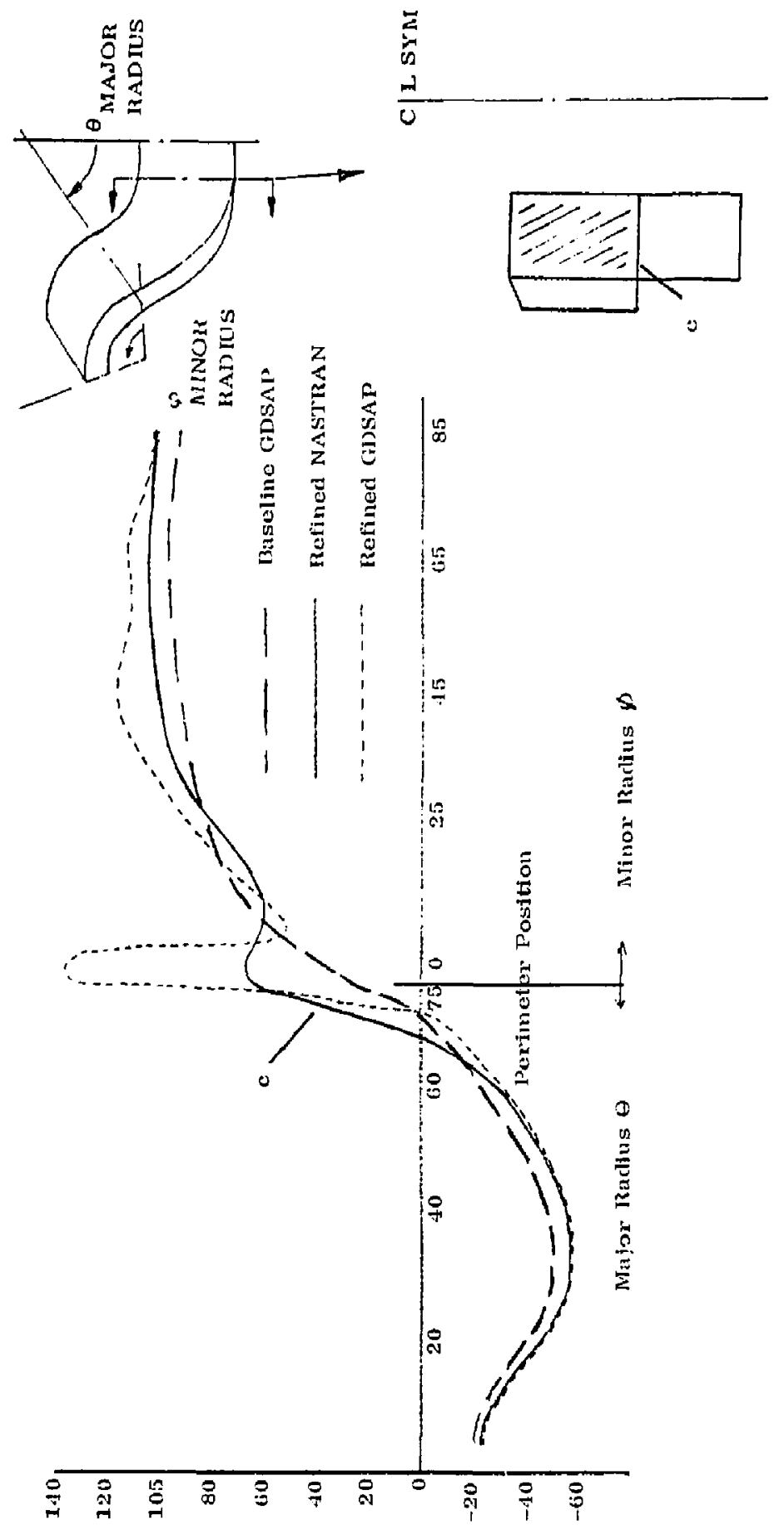

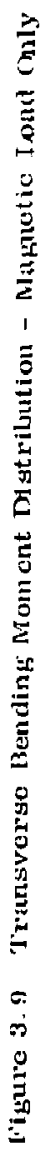

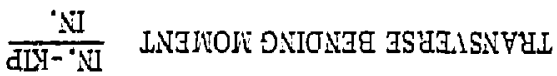




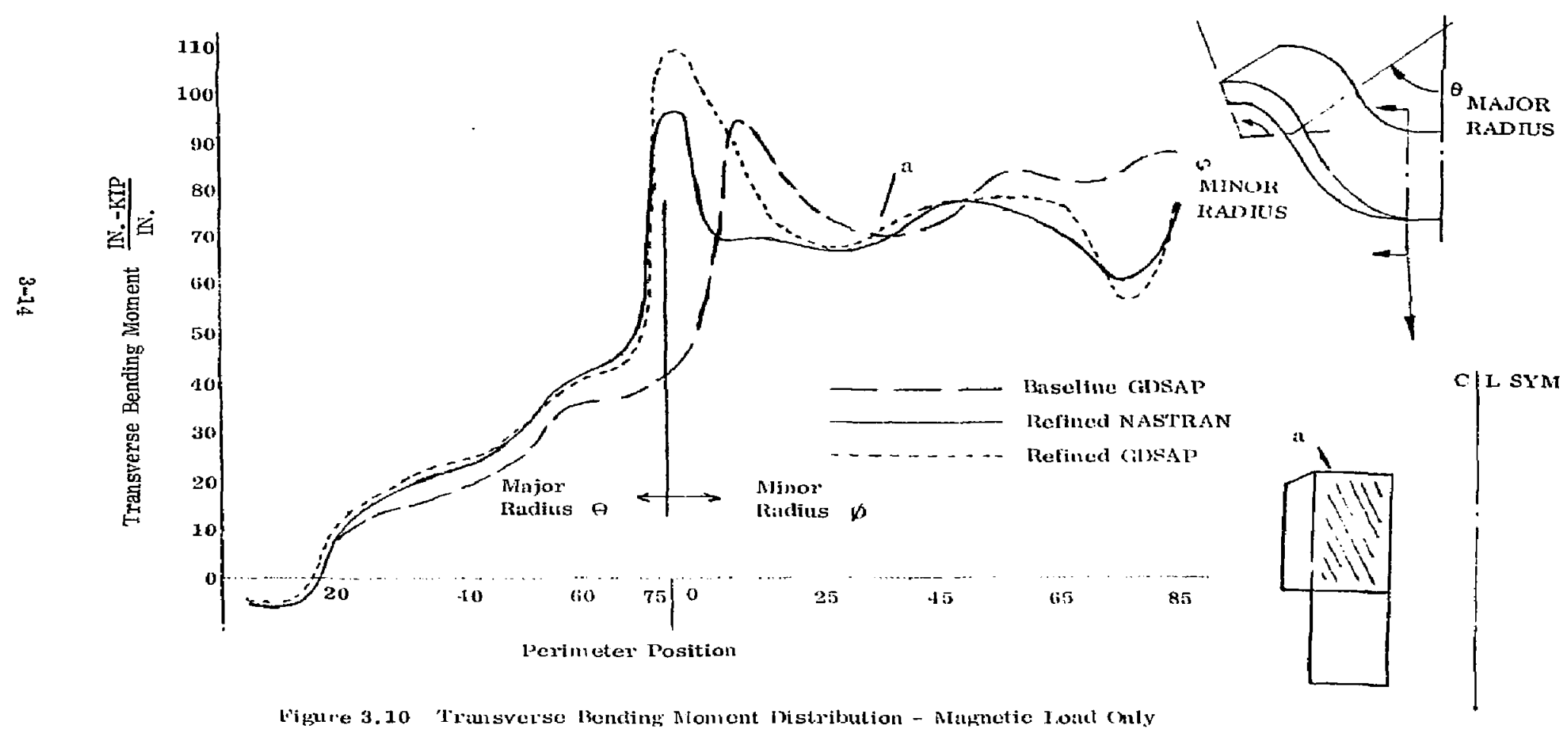




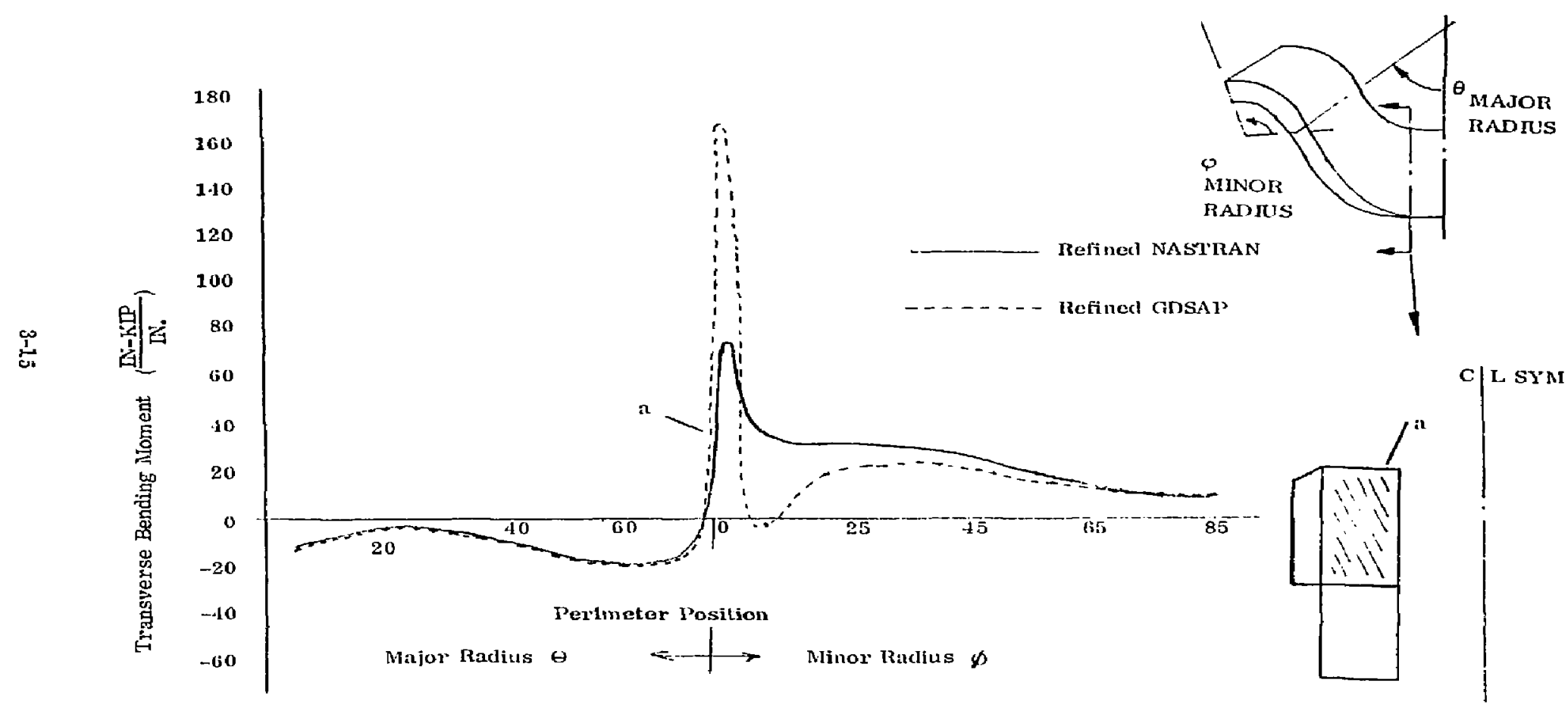

Iigure 3.11 - Traulsverse Bendtng Moment Distributioı 


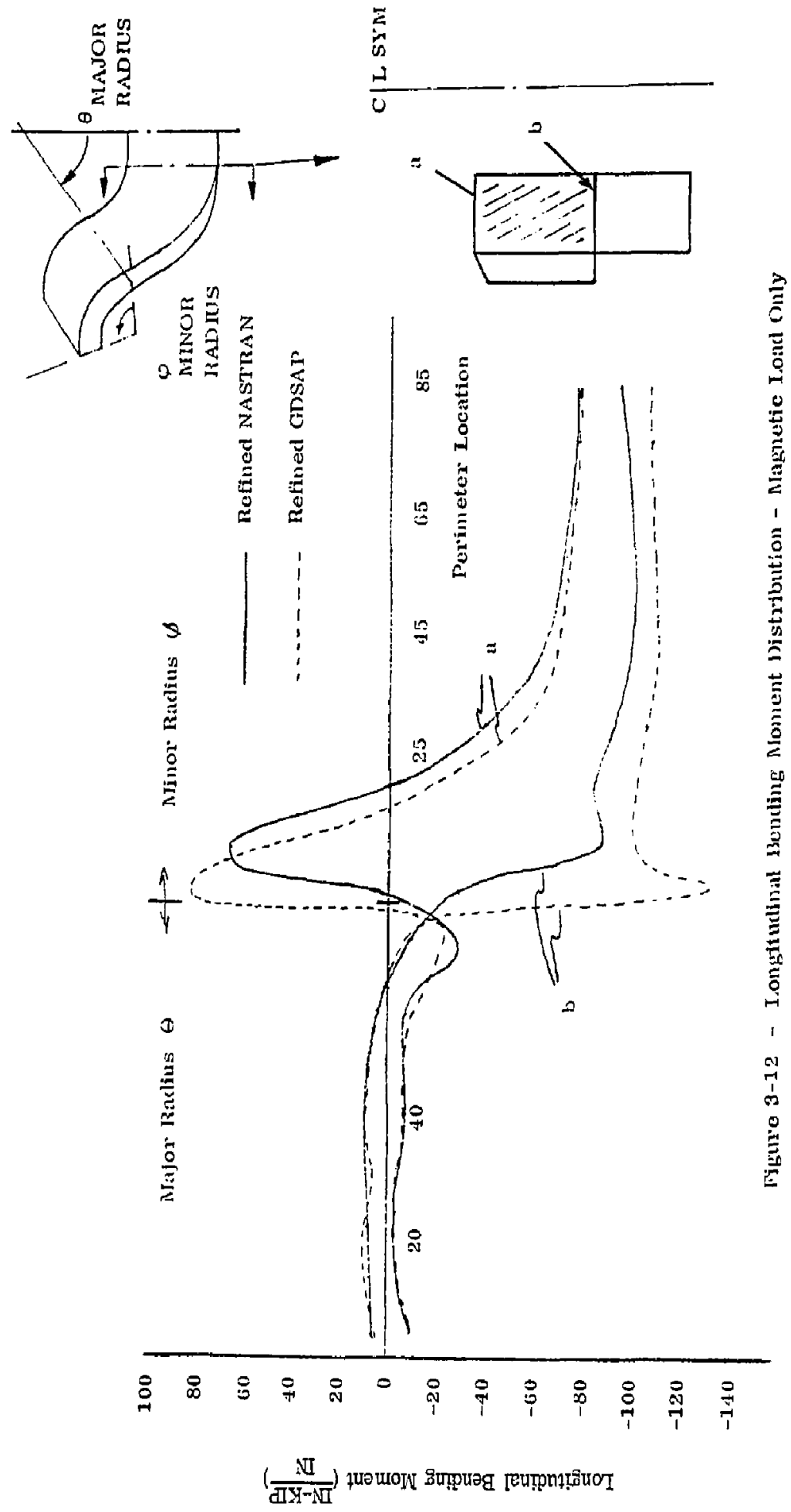




\section{REFERENCES}

1. Structural Analysis of the Magnet System for Mirror Fusion Test Facility (MFTF), GD/C Report No. CASD-LIL-78-003, by J. Wohlwend, et al, October 1978.

2. Solid SAP: User's Manual P5679 by M. J. Cronk, Report No. CASD-CH-74-008, October, 1977.

3. MSC/NASTRAN Liser's Manual, by MeCormick, Volumes I and II, May 1976.

4. EFFI Load Data, MFTF-MAG FORCE (5x12 Model), supplied by Lawrence Livermore Laboratories, MLMAGF, 15 June 1978.

5. MFTF Conductor Bundle Comisaction Tests, LLL memorandum, MIF-TR-1.1.2.6, 25 January 1979, by John Horvath. 